\title{
O PLANEJAMENTO DE ENSINO PARA ALÉM DOS ELEMENTOS ESTRUTURANTES DE UM PLANO DE AULA
}

\author{
TEACHING PLANNING BEYOND A LESSON PLAN STRUCTURE ELEMENTS
}

\author{
Lívia Santos Brisolla \\ Renata Machado de Assis²
}

\begin{abstract}
Resumo: Este artigo tem por objetivo apresentar, do ponto de vista teórico, as concepções, as contribuições e os elementos de uma organização didática da aula que fundamentam o planejamento de ensino, por meio dos resultados de uma revisão integrativa de literatura. Assim, propõe-se repensar sua relevância para a organização do trabalho pedagógico da escola e da sala de aula a fim de recuperar o seu espaço no âmbito educacional. Defendese o planejamento de ensino como um processo contínuo de reflexão, previsão e decisão acerca do trabalho pedagógico com vistas a aproximar escola e realidade social. Na discussão, aponta-se para a necessidade de transcender a atividade de planejamento que se apresenta burocrática, fragmentada e instrumental para percebêla como um processo participativo, reflexivo, flexível, integrador e contínuo. Portanto, conclui-se a necessidade de repensar o planejamento de ensino para além dos elementos estruturantes de um plano de aula, que integre a escola e o contexto social na contramão da fragmentação do conhecimento, dos processos e das relações.
\end{abstract}

Palavras-chave: Planejamento de ensino. Organização do trabalho pedagógico. Elementos estruturantes de um plano de aula.

Abstract: This article aims to present the class didactic organization conceptions, contributions and elements that base a teaching planning from a theoretical point of view, through the results of an integrative literature review. Thus, it proposes to rethink its relevance to the pedagogical school and classrom wok organization to recover its space in the educational scope. Teaching planning is defended as an continuous process of reflection, prediction and decision about pedagogical work with a view to bringing school and social reality. In the discussion, the need to transcend the bureaucratic, fragmented and instrumental planning activity to perceive it as a participatory, reflexive, flexible, integrative and continuous process is pointed out. Therefore, it concludes the necessity to rethink the teaching planning beyond a lesson plan structure elements that integrates the school and the social context against the fragmentation of knowledge, processes and relationships.

Keywords: Teaching planning. Pedagogical work organization. A lesson plan structure elements.

Resumen: Este artículo tiene como objetivo presentar, desde un punto de vista teórico, las concepciones, aportes y elementos de una organización didáctica de la clase que sustentan la planificación de la enseñanza, a través de los resultados de una revisión integradora de la literatura. Así, se propone repensar su relevancia para la organización del trabajo pedagógico de la escuela y el aula con el fin de recuperar su espacio en el ámbito educativo. La planificación de la docencia se defiende como un proceso continuo de reflexión, predicción y decisión sobre el trabajo pedagógico con miras a acercar la realidad escolar y social. En la discusión se señala la necesidad de trascender la actividad de planificación que es burocrática, fragmentada e instrumental para percibirla como un proceso participativo, reflexivo, flexible, integrador y continuo. Por tanto, se concluye la necesidad de repensar la planificación docente más allá de los elementos estructurantes de un plan de lecciones, que integre la escuela y el contexto social frente a la fragmentación de saberes, procesos y relaciones.

Palabras clave: Planificación de la docencia. Organización del trabajo pedagógico. Estructuración de elementos de un plan de lección.

\footnotetext{
1 Doutora em Educação pela Universidade Federal de Goiás. E-mail: liviabrisolla@gmail.com. Orcid: https://orcid.org/0000-0001-8919-8276.

2 Doutora em Educação pela Universidade Federal de Gioás e docente da mesma universidade. E-mail: renatafef@hotmail.com. Orcid: https://orcid.org/0000-0002-2075-9319.
} 


\section{CONSIDERAÇÕES INICIAIS}

Este artigo apresenta os resultados de uma revisão integrativa de literatura, desenvolvida por meio do levantamento teórico de publicações disponíveis em livros, periódicos, dentre outros referenciais. Este tipo de metodologia visa sintetizar as produções científicas sobre determinado tema, de forma abrangente, sistemática e ordenada, permitindo que se tenha acesso de forma ampliada ao assunto/tema/questão (ERCOLE; MELO; ALCOFORADO, 2014).

O planejamento de ensino é alvo de diferentes significados e perspectivas que foram se adequando às concepções teóricas e pedagógicas no decorrer das mudanças educacionais. A produção sobre esse assunto teve seu auge na década de 1990 e os autores mais citados são: Turra et al (1995), sendo a primeira edição de 1975, Piletti (1990), Lopes (1991), Vasconcellos (1995), entre outros. Isto revela a necessidade de releituras e outras pesquisas contemporâneas, como também, de trazer o planejamento para o debate educacional, especialmente no tocante às suas contribuições e o lugar que ocupa na organização do trabalho pedagógico.

Silva (2017), em estudos mais recentes sobre a organização do trabalho pedagógico, assevera a forma ambígua como vem sendo abordado o planejamento pelos docentes e pela escola: se para uns prepondera uma visão simplificada de que planejar é definir objetivos, conteúdos e métodos, para outros, permanece a ideia de que realizar planejamento é uma ação já superada. Por isso a relevância de repensar a ideia de planejamento a fim de recuperar o seu espaço na escola, compreendendo seu contexto, especificidades, níveis e contribuições para a organização pedagógica da escola e da sala de aula.

A ideia de planejamento exige uma visão abrangente do universo educacional considerando as relações com a realidade social, política, cultural, econômica e escolar, as tendências pedagógicas, as finalidades da educação, o currículo escolar, o projeto político-pedagógico e, sobretudo, com a organização didática da aula. Para tanto, é fundamental: 1) ampliar a ideia de planejamento a partir da visão da organização capitalista do trabalho, entendendo o planejamento como produto de uma sociedade organizada em torno do capital que reproduz um trabalho pedagógico nos moldes da pedagogia tecnicista; 2) compreender a partir da organização do trabalho pedagógico a concepção de planejamento na contramão de uma visão dicotômica da totalidade, de unidade, como processo em constante movimento. Assim, busca-se a ideia de planejamento como processo contínuo de integração da escola e do contexto social (LOPES, 1991; VEIGA, 2004). É, portanto, um processo reflexivo e integrador que envolve não somente o compromisso docente, mas, especialmente, a participação do coletivo da escola; 3) a partir dessas condições, torna-se essencial relacionar e discutir os elementos estruturantes para uma organização didática da aula, por conseguinte, discutir sua disposição, relações e contribuições para o trabalho escolar e docente.

Este artigo se estrutura em quatro momentos. No primeiro, é abordada a organização do trabalho pedagógico, que sob as bases capitalistas incorpora a fragmentação dos processos e da visão de unidade promovendo um distanciamento do homem com a realidade. No segundo, a partir dessa ótica, são apresentados os níveis de planejamento, levando em consideração a abrangência e o universo de especificidades de inter-relações. No terceiro discute-se a ideia de planejamento de ensino, abordando suas concepções e contribuições e destaca-se, ainda, a compreensão de plano e projeto. No quarto é apontada a importância do planejamento de ensino para a organização didática da aula para além da prática sequencial de etapas, ou seja, ultrapassando a concepção mecanicista de planejamento de ensino (VEIGA, 2008).

\section{ORGANIZAÇÃO DO TRABALHO PEDAGÓGICO: pressuposto fundamental}

A escola é uma organização socialmente construída que exerce uma função social e incorpora as necessidades da sociedade capitalista, consequentemente, reflete na sua essência as exigências e contradições dessa sociedade. Não dá para pensar a escola e sua organização pedagógica fora dessa realidade social em que se está inserido, pois "sendo um instrumento de reprodução das relações de produção, a escola na sociedade capitalista necessariamente reproduz a dominação e exploração" (SAVIANI, 2003, p. 30).

Por essa linha teórica de pensamento, a organização do trabalho pedagógico retrata o modo como 
a nossa sociedade organiza o trabalho (VEIGA, 2008; FREITAS, 1995; VILLAS BOAS, 2017). Essa relação entre a organização do trabalho pedagógico e a organização capitalista serviu de base para o desenvolvimento da pedagogia tecnicista na década de 1960. Inspirados "nos princípios da racionalidade, eficiência e produtividade essa pedagogia advoga a reordenação do processo educativo de maneira a torná-lo objetivo e operacional" (SAVIANI, 2003, p. 12). Com efeito, a organização pedagógica dos processos de ensino, afetada pela concepção tecnicista, direcionava o ensino/aprendizagem tendo como base a organização do trabalho nas fábricas, preparando, assim, o discente para o mundo do trabalho.

Não obstante, esse processo promoveu um distanciamento do sujeito da totalidade, da interrelação entre os processos, da visão de unidade, ao mesmo tempo em que o aproximou de uma realidade dicotômica, levando à separação entre sujeito e objeto, universal e particular, conteúdo e forma, teoria e prática, ensino e pesquisa, docente e discente. No plano pedagógico, de acordo com Villas Boas (2017), provoca uma cisão entre os que pensam e planejam e os que executam. A autora cita alguns fatos que justificam essa cisão quando o docente "recebe prontos para apenas aplicar: propostas pedagógicas, projetos, instrumentos de avaliação, pacotes pedagógicos. [...] faz do livro didático seu plano de trabalho, sem pesquisar outras informações" (VILLAS BOAS, 2017, p.15).

Essa forma de separação vai ao encontro da ideia de afastar o docente do trabalho de planejar suas ações. No entender de Villas Boas (2017), o fato de receber tudo pronto indica que o docente pouco precisa fazer para colocar em prática o que já foi determinado, planejado e orientado, sendo apenas necessário seguir as instruções. Isso demonstra uma simplificação, mecanização e padronização do trabalho docente com o apoio de materiais, apostilas e treinamentos. Ademais, colaborou para a redução do poder de decisão docente, como também, a desvalorização do seu trabalho quando planejado por outras pessoas, tendo apenas que executar. A crítica da autora a essa organização capitalista do processo de trabalho está na obediência docente a rituais repetitivos, tais como: fazer chamada, copiar do quadro, fazer cabeçalho, longos deveres de casa, entre outros.

É muito possível que estejamos vivenciando o aparecimento de um neotecnicismo no plano da organização do trabalho pedagógico. Da mesma forma que uma das palavraschave no plano da crítica social que o neoliberalismo faz é "eficiência", também no plano da organização do trabalho pedagógico ela poderá ser retomada, na forma de um neotecnicismo: avaliação das escolas, avaliação do professor, distribuição de verbas e salários de acordo com estas avaliações, revisão curricular; ênfase em uma metodologia pragmática e despolitizada para obter resultados em sala de aula - ou seja, desgarra-se a análise da escola de seus determinantes sociais e assume-se que a escola vai mal porque Ihe faltam controle, eficiência, método, racionalização e treinamento para o professor. Aceita esta premissa, o problema da educação deixa de ser político para ser técnico. Daí o termo tecnicismo. Mas, como nós já vimos este filme na década de setenta, daí o termo neotecnicismo (FREITAS, 1991, p.12, grifos nossos).

Apesar de o texto ser da década de 1990, o exposto é atual por evidenciar a volta do neotecnicismo no interior das práticas pedagógicas de muitos docentes, não somente nas avaliações, mas também, na dimensão técnica do planejamento com plano de aula padronizado e instrumentalizado. O neotecnicismo revela uma reorganização do trabalho pedagógico ancorado no discurso ideológico de eficiência, produtividade e racionalidade que obscurece a dimensão política e pedagógica.

Outro ponto que se pode analisar, a partir da citação, é o consequente afastamento da escola de seus determinantes sociais, ou seja, promover um distanciamento da escola com a realidade e seus problemas sociais. Lopes (1991) já discutia essa questão esclarecendo que o planejamento do ensino se mostra desvinculado da realidade social e apoiado em práticas mecânicas e burocráticas. Tal afastamento é justificado por meio de um discurso ideológico da necessidade da eficiência, método e treinamento docente para obscurecer os reais problemas da escola e uma organização pedagógica ancorada no neotecnicismo, como relata o autor.

Porém, os processos educacionais são contraditórios. A organização do trabalho pedagógico desempenha um papel que, por um lado, regula o trabalho pela conformidade às regras fixadas, mediante 
procedimentos formalizados, e de outro pode propiciar o rompimento da divisão do trabalho, a fragmentação e o controle. A contradição se constitui na complexidade e não linearidade dos processos que são, antes de tudo, processos que se embatem, se fundem e se contradizem e que podem levar a resistência e/ou a acomodação de alguns ou de todos os envolvidos na organização do trabalho pedagógico.

Compreende-se, a partir de Freitas (1995) e Villas Boas (2017), que a organização do trabalho pedagógico pode ser entendida em duas direções: trabalho pedagógico da escola e trabalho pedagógico de sala de aula (trabalho docente). A organização do trabalho pedagógico da escola e de sala de aula se apoia mutuamente, pois tanto da escola como de sala de aula representa a luta pelo mesmo objetivo de ensino/aprendizagem de todos.

\section{NÍVEIS DE PLANEJAMENTO}

A ideia de planejamento persegue um objetivo, uma finalidade, por isso, é preciso saber onde se deseja chegar e o que se deseja ensinar. $O$ ato de planejar não se resume à ação mecânica de um trabalho burocrático com o preenchimento de fichas sobre os conteúdos, objetivos, metodologias, recursos e avaliação. Nesse sentido, o planejamento corresponde ao conjunto organizado de intenções/ações que busca alcançar determinado objetivo. É um processo contínuo de tomada de decisão (VASCONCELLOS, 1995) constituído e inerente à prática pedagógica.

O planejamento de ensino faz parte de uma subdivisão do processo em níveis de abrangência. Uma visão mais tradicional é apresentada por autores como Turra et al (1995) e Piletti (1990), que dividem o planejamento em três níveis: educacional, curricular e ensino.

O planejamento educacional é o mais abrangente e engloba as políticas públicas e os governos federais, estaduais e municipais como, por exemplo, o Plano Nacional de Educação (PNE) que ratifica as intenções, diretrizes, objetivos, normativas e as finalidades educacionais que se deseja alcançar. Em nível estadual e municipal o planejamento se aproxima de uma política de descentralização do poder que leva em consideração as características culturais, sociais, econômicas e o respeito à diversidade regional/local. O planejamento educacional delibera uma política de educação que visa conduzir o desenvolvimento geral do país no conjunto de proposições com objetivos de longo prazo (PILETTI, 1990).

O planejamento curricular refere-se à organização no âmbito escolar com base na realidade e especificidades de cada escola. Na visão de Piletti (1990) deve-se levar em conta as diretrizes estabelecidas pelo Conselho Estadual de Educação (CEE). O planejamento curricular inclui a escola, as experiências dos discentes e a dinâmica do processo educativo. Para Turra et al (1995, p.17), é a "previsão global e sistemática de toda ação a ser desencadeada pela escola, em consonância com os objetivos educacionais, tendo por foco o aluno". Seu principal documento norteador são os Parâmetros Curriculares Nacionais (PCN).

O planejamento de ensino é construído a partir do planejamento curricular (TURRA et al, 1995; PILETTI, 1990) e envolve a organização das ações, previsão e os meios para alcançar os resultados desejáveis. O planejamento de ensino é o que dá sentido ao trabalho docente como eixo norteador das práticas pedagógicas. De acordo com Turra et al (1995), sua referência, além do planejamento curricular, são as dimensões: filosófica, que apresenta os objetivos da escola; psicológica, que aponta o desenvolvimento discente, suas possibilidades e interesses; e social, que indica características do espaço social-econômico-cultural dos discentes. Entretanto, Luckesi (2011) avalia as preposições da autora como sendo uma análise acrítica por não trazer para o debate nenhuma referência à discussão política da ação que se pretende realizar.

A proposta de Vasconcellos (1995) de planejamento em diferentes níveis de abrangência inclui: o planejamento do sistema de educação, que é realizado em nível nacional, estadual ou municipal; o planejamento da escola, que engloba o plano integral da instituição, portanto, é o Projeto Políticopedagógico (PPP); o planejamento curricular, que é a proposta geral das experiências de aprendizagens incorporadas aos componentes curriculares; o projeto de ensino-aprendizagem, que se refere ao planejamento da prática docente e se subdivide em projeto de curso e plano de aula; o projeto de trabalho, que é o planejamento dos projetos de aprendizagem; e, por fim, o planejamento setorial que 
trata do plano dos níveis intermediários como cursos, departamentos, áreas e/ou dos serviços no interior da escola que envolva a direção, coordenação, secretaria, entre outros.

Outra proposta de organização do processo de planejamento em níveis de abrangência é apresentada por Silva (2017), que as subdivide em: macro, meso e micro. O nível macro corresponde ao sistema e redes de ensino. É uma visão macro do sistema na esfera do Ministério da Educação (MEC) por meio do PNE, do Conselho Nacional de Educação (CNE) e dos órgãos estaduais e municipais. Já o nível meso engloba o trabalho nas escolas, tendo como base o nível macro: "traduz as políticas públicas do nível macro, fazendo a intermediação entre estas e as demandas locais na implementação das políticas" (SILVA, 2017, p. 27). E, por fim, o nível micro, que envolve o planejamento da escola e sala de aula e o PPP.

Pode-se conceber a divisão em níveis macro, meso e micro como um conjunto de níveis indissociáveis das relações e processos de planejamento. Cada um desses níveis possui um universo de especificidades que se inter-relacionam e necessitam um do outro para realizarem um trabalho integrado e de qualidade. A comunicação e a interação entre esses níveis de planejamento precisam estar em harmonia com a organização do trabalho pedagógico da escola e de sala de aula, uma vez que o planejamento é caminho que aproxima a finalidade da educação na perspectiva de um projeto de concepção de mundo/sociedade com vistas à transformação.

\section{PLANEJAMENTO DE ENSINO: concepções, projeto, plano e contribuições}

A ideia de planejamento está associada ao que se deseja realizar, transformar ou manter, pois as "concepções sobre planejamento tanto podem estar ligadas às ideias de transformação como às de manutenção de realidades ou situações existentes" (TURRA et al, 1995, p. 273). O planejamento de ensino é um processo contínuo de reflexão, previsão e decisão acerca da organização do trabalho pedagógico com a finalidade de orientar a prática docente, visando aproximar o discente, dialeticamente, do que é concreto, ou seja, da realidade, buscando transformá-lo. Para Vasconcellos (1995), o planejamento deve ser entendido como um instrumento capaz de intervir em uma situação real para transformá-la.

Na concepção de Lopes (1991), o planejamento de ensino é elemento integrador entre escola e contexto social, voltado para a transformação social. Essa é uma perspectiva crítica que busca na problemática social, econômica e política elementos de referência para o planejamento, como forma de refletir, intervir e transformar a realidade, pois "planejamos para intervir na realidade" (SILVA, 2017, p. 29). Contudo, intervir exige compromisso docente com o pedagógico, com a realidade social e política na busca de uma educação integradora. Lopes (1991, p. 50) afirma "que uma educação integradora, onde professores e alunos produzam conhecimentos a partir da participação da escola na sociedade e viceversa, estará formando efetivamente um educando com possibilidades de contribuir concretamente para a transformação da sociedade".

A ação de planejar não é uma atividade neutra (LOPES, 1991; LUCKESI, 2011), por isso, a concepção de ensino crítico e transformador é condição primordial para a construção de um trabalho de planejamento com base na participação e problematização, "que ouse dar oportunidade para o aluno reelaborar os conteúdos do saber sistematizado, com vistas à produção de novos conhecimentos" (LOPES, 1991, p. 51). Essa é a concepção de um planejamento de ensino participativo, com a valorização da participação do coletivo com diálogo entre os docentes, os discentes, os pais e o coletivo da escola. Decorre daí uma organização do trabalho pedagógico coletiva, participativa e integrada, que busque a reflexão e o envolvimento dos profissionais da escola nos processos de planejamentos e projetos a serem desenvolvidos.

Na visão de Turra et al (1995) o planejamento participativo necessita de um olhar crítico do conhecimento, no sentido de questionar a organização burocrática do trabalho. Um planejamento participativo implica a eliminação da divisão do trabalho pedagógico e tomada de decisão coletiva. Assim, o planejamento

é interativo no sentido de que a organização (e as pessoas que nela atuam) é o sujeito do plano e, na busca de seus objetivos, ela própria se modifica e encoraja transformações 
(também das pessoas). Planejar assim não requer previsão formal, nem se constitui numa sequência de ações para alcance de objetivos (TURRA et al, 1995, p. 275).

A participação é condição primordial no processo de planejamento de ensino uma vez que contribui para superar a fragmentação do trabalho (SILVA, 2017). No entanto, essa não é uma tarefa fácil, pois a fragmentação do processo de planejamento tem se mostrado um instrumento técnico/burocrático que não reflete continuamente. É o que se evidencia nas críticas de Saviani (2003), Silva (2017), Lopes (1991) e Luckesi (2011) acerca da padronização do sistema de ensino com esquemas e componentes tecnicamente recomendáveis na elaboração de um planejamento. Nessa direção, Luckesi (2011, p.126) chama a atenção para os roteiros técnicos cada vez mais eficientes em que "pouco ou nada se discute a respeito do significado social e político da ação que estão na base do problema a ser enfrentado, assim como não se discutem as possíveis consequências político-sociais que decorrerão da execução do projeto em pauta". Na análise do autor, reconhecer o ato de planejar como opção filosófica-política demanda escolha, decisão e comprometimento.

As reflexões/discussões sobre o planejamento se materializam em projetos e planos com o objetivo de conduzir a prática docente. O projeto, nas palavras de Veiga (2004, p. 69), "é a ação consciente e organizada porque é elaborado com vistas ao futuro. Projetar é lançar-se para o futuro. É um instrumento que visa orientar os desafios do futuro. O futuro não está dado, não é algo pronto". Dessa forma, o projeto pedagógico caracteriza-se como um projeto de vida com base na sociedade atual e nas perspectivas e finalidades educacionais que se busca construir. Isso significa que o projeto pedagógico aponta uma direção, uma ação intencional, "com um sentido explícito, com um compromisso definido coletivamente. Por isso, todo projeto pedagógico da escola é, também, um projeto político por estar intimamente articulado ao compromisso sociopolítico com interesses reais e coletivos" (VEIGA, 2004, p. 14-15).

O projeto não se resume a um plano de desenvolvimento de ações, mas no processo de (re)pensar as ações e responsabilidades coletivas da escola e comunidade. Nesse sentido, o projeto pedagógico traduz a organização do trabalho pedagógico da escola, já o plano traduz essa organização em sala de aula.

O plano é a sistematização, a negociação, a materialização das ideias/reflexões do planejamento em um documento, é o resultado do planejado. Os planos "são registros do processo de elaboração consciente e crítica do planejamento e sistematizam os objetivos, conteúdos, procedimentos e avaliação a serem desenvolvidos por professores e estudantes em um determinado período de tempo" (SILVA, 2017, p. 30). Conforme atestam Piletti (1990) e Turra et al (1995), o professor pode organizar três tipos de planos pelo nível de abrangência: plano de curso, de unidade e de aula. O plano de curso é global, é a previsão de uma gama de conhecimentos a ser alcançado por uma turma em determinado período. $\mathrm{O}$ plano de unidade é uma especificação do plano de curso. O plano de aula é a sequência de tudo o que vai ser desenvolvido em dia, ou seja, as realizações diárias visando a concretização dos planos anteriores. No entender de Vasconcellos (1995, p. 124), o plano de aula é "a proposta de trabalho do professor para uma determinada aula ou conjunto de aulas [...]. Corresponde ao nível de maior detalhamento e objetividade do processo de planejamento didático. É a orientação para o que fazer no cotidiano".

Por essa síntese percebe-se que o período de planejamento em cada um dos planos se diversifica, assim, o plano de curso é mais amplo, podendo ser anual ou semestral; já o plano de unidade é menor, bimestral ou mensal; e o plano de aula é mais próximo e específico do dia letivo que se aproxima. Todavia, para que esses planos sejam eficazes dependerá, na visão de Turra et al (1995), da organização, coerência e flexibilidade. A construção de um plano preza por uma organização e coerência a fim de evitar receitas prontas e a improvisação; nesse viés, contribui para a realização dos objetivos desejados. A flexibilidade possibilita os reajustes necessários, sendo assim, permite mudanças, ressalvas, adicionar ou suspender algum elemento previsto.

Em sentido mais amplo, para Silva (2017), o plano de aula se efetiva tendo como eixo norteador o PPP e os programas de aprendizagem elaborados por diferentes docentes organizados por áreas de conhecimento e/ou por anos de escolarização. A autora percebe o plano de aula como um desdobramento dos programas de aprendizagem a serem realizados com base nos objetivos e aspirações 
ISSN 1983-1579

ufpb.1983-1579.2020v13nEspecial.45583

http://periodicos.ufpb.br/ojs2/index.php

do PPP e da organização curricular, com vistas ao acesso ao conhecimento, saberes e experiências discentes. Já os programas de aprendizagem focalizam as aprendizagens e as ações discentes voltadas para a organização didática da aula no intuito de desenvolver as dimensões ensinar, aprender e avaliar, em uma concepção crítica/reflexiva que preza pela aprendizagem e desenvolvimento discente.

Aqui se questiona: quais são os benefícios e contribuições para o docente e para a escola da sistematização do processo de planejamento no formato de planos? Em que contribui para a melhora da prática docente? E quais são os benefícios para a escola? Para sinalizar algumas ideias que esclarecem esse questionamento, essa discussão se sustenta nas produções de Silva (2017), Piletti (1990) e Turra et al (1995).

O planejamento de ensino, na perspectiva crítica e transformadora, fornecerá ao docente maior segurança para sua prática educativa no sentido de acolher as exigências, os problemas e desafios que ocorrem na sala de aula, na escola e na comunidade em geral. Além disso, Silva (2017) apresenta um delineamento que condiz com a perspectiva crítica e transformadora.

a) transparência ao trabalho docente e discente, favorecendo o acompanhamento e a avaliação desse trabalho pelos profissionais da escola, pelos estudantes e pela comunidade;

b) organização e formalização das ações do trabalho docente, subsidiando as equipes pedagógicas a pensarem ações de formação continuada que apoiem os professores e busquem as condições materiais e humanas para a execução do planejado;

c) meio de o professor visualizar o percurso do trabalho desenvolvido, identificar as fragilidades e replanejar as ações, bem como os avanços e a continuidade do concebido;

d) forma de o professor ter seu trabalho valorizado e compartilhado, contribuindo para sua profissionalização docente;

e) fortalecimento de trocas entre os professores e compreensão da ação de ensinar e de aprender, criando um sentido de grupo como coletivo de pessoas que se reconhecem em sua singularidade, exercendo ação interativa com objetivos comuns e compartilhados (p. 30).

Piletti (1990) salienta outros pontos: evitar a rotina e improvisação; alcançar os objetivos almejados; promover a eficiência do ensino; garantir maior segurança e economizar tempo e energia. Tais pontos servem para orientar a prática docente, atendendo às necessidades apresentadas pelos discentes. Portanto, o planejamento de ensino é essencial tanto para o docente quanto para a escola, visto que direciona o caminho a ser percorrido e possibilita organizar, refletir, prever e decidir para atingir os objetivos e finalidades traçadas.

Para Turra et al (1995) o planejamento de ensino contribui para: racionalizar as atividades; garantir um ensino efetivo; verificar o ritmo do processo educativo; e fornecer maior segurança ao docente na realização dos objetivos previstos. Na esteira desta vertente convergem os objetivos educacionais para uma leitura que transcenda o olhar específico da aula e integre o contexto social, cultural, escolar e econômico.

\section{ELEMENTOS ESTRUTURANTES DO PLANO PARA UMA ORGANIZAÇÃO DIDÁTICA DA AULA}

A partir da concepção de um planejamento de ensino participativo e integrador entre a escola e o contexto social percebe-se, a partir do exposto, que o planejamento de ensino é um processo contínuo de reflexão, previsão e decisão que reflete uma organização do trabalho pedagógico da escola e da sala de aula. É, portanto, nessa linha que a sistematização didática da aula aparece apoiada na organização do trabalho pedagógico em sala de aula.

Veiga (2008) define a organização didática da aula como um projeto colaborativo que procura dar conta do processo didático em toda sua abrangência. É um projeto de colaboração e interação entre os docentes e discentes, pautado em relações não hierarquizadas com liderança compartilhada e com corresponsabilidade. 
O objetivo principal da organização didática da aula é possibilitar um trabalho mais significativo e colaborativo, consequentemente, mais comprometido com a qualidade das atividades previstas. A organização didática da aula como projeto colaborativo de ação imediata representa o produto de um movimento processual de reflexão e decisão, de comprometimento e criticidade (VEIGA, 2008, p. 274).

A organização didática da aula como ação colaborativa pressupõe os seguintes princípios: contextualização, flexibilidade, objetividade, colaboração e exequibilidade. Esses princípios embasam as características de uma aula: de forma colaborativa, com a participação discente; dá conta do processo didático em sua abrangência; orienta a reflexão com base na prática e para a prática; considera a aula em sua totalidade; evita o improviso docente; articula as ações com o projeto político-pedagógico e ao programa de aprendizagem ou plano elaborado coletivamente; dá significado ao processo didático pelo diálogo (VEIGA, 2008).

Nesse sentido, a aula não constitui um fim em si mesmo, compreende um processo educativo, histórico e social que pressupõe organização, planejamento e intencionalidades. A "aula é constituída de um sistema complexo de significados, de relações e intercâmbios que ocorrem num cenário social que define demandas da aprendizagem" (VEIGA, 2008, p. 269). É um projeto que busca aproximar a escola da realidade social por meio de um processo de colaboração entre os docentes e os discentes. Para tanto, a realidade é o ponto de partida e de chegada que se desenvolve com base nos seguintes questionamentos: para quê? O quê? Como? Com quê? Como avaliar? Para quem? Quem? Quando? Onde? Esses questionamentos incluem saberes, culturas, experiências e conhecimentos organizados em uma estruturação didática composta por objetivos, conteúdos, metodologias, recursos e avaliação.

Silva (2017, p. 31) alerta que primeiro "os professores precisam ter clareza sobre quais são as intencionalidades sociopolíticas da educação e suas metas gerais apresentadas na legislação, no projeto político-pedagógico da escola e no currículo escolar". As intencionalidades educativas impõem uma determinada concepção de educação que norteia, conduz o processo formativo do indivíduo, por conseguinte, da sociedade. São intenções da ação educativa que ocorrem, consoante expõe Veiga (2008), em quatro níveis de decisão: no político, na gestão educativa, no pedagógico e na prática pedagógica. A construção do plano de aula se dá a partir dos elementos estruturantes: objetivos, conteúdos, metodologia, avaliação e recursos desenvolvidos em um prazo de tempo e de espaço determinado. $O$ plano de aula é a sistematização desses elementos estruturantes para a organização da aula.

Os objetivos são formulações que advém das intencionalidades, é o guia que orienta o processo didático (VEIGA, 2008). Silva (2017) reitera essa concepção e acrescenta que os objetivos devem incluir a capacidade humana cognitiva, afetiva, psicomotora de relações interpessoais e de inserção social. Definir os objetivos requer repensar a realidade da escola, da comunidade, dos discentes e suas perspectivas e fins educacionais.

Para Silva (2017) os conteúdos são os conhecimentos científicos, culturais e as experiências que apontam uma formação discente relacionando-se com os objetivos. Conteúdo e objetivo estão relacionados, de acordo com Veiga (2008, p. 280), sendo o conteúdo "uma concretização dos objetivos, ou seja, são meios para sua consecução". Ambas as pesquisadoras salientam a reflexão conjunta dos objetivos e conteúdos. Para organizar o conteúdo é preciso tomar decisões e refletir coletivamente acerca das indagações: para que? O que ensinar? Para Turra et al (1995, p.33) "os conteúdos representam o conjunto, rico e variado, de conhecimentos, que possibilita ao aluno desenvolver suas capacidades, ao mesmo tempo que lhe esclarece suas relações com os outros e com o meio onde vive".

A metodologia compreende "dispositivos que visam favorecer a construção de aprendizagens mais significativas, com abertura da cultura curricular às culturas locais" (SILVA, 2017, p. 33). Na análise de Veiga (2008, p. 282), o método de ensino não é um caminho linear para alcançar os objetivos, é “o caminho que medeia o ato de ensinar e o ato de aprender". Em outra perspectiva, Libâneo (1994) considera a metodologia uma forma de intervenção didática articulada aos objetivos e conteúdos. Essa articulação é concebida com unidade objetivo/conteúdo/método e, como tal, compõe a linha mestra de compreensão do processo didático. 
Diferente de Libâneo (1994), Turra et al (1995) e Piletti (1990), que caracterizam a avaliação como um instrumento que acontece ao final do processo pedagógico e que determina o nível de resultados alcançados, Freitas (1995) dá destaque à avaliação e a coloca como categoria estruturante da organização do trabalho pedagógico. É a avaliação que sustenta os rumos das aprendizagens, nas quais toda a estrutura pedagógica deve se estabelecer. Partindo desse pensamento, percebe-se a avaliação como orientadora de toda prática que acompanha o trabalho pedagógico, porque "está presente em todos os momentos da sala de aula, devendo ser sistematizada no plano como orientadora de toda prática; ela inicia, acompanha e finaliza o trabalho pedagógico" (SILVA, 2017, p. 33).

Os recursos são os meios utilizados pelo docente para criar condições que favoreçam as aprendizagens dos discentes, contribuindo para o alcance dos fins da educação (SILVA, 2017). A organização do espaço de aula em consonância com a metodologia e o recurso configura um espaço de ensino-aprendizagem. Isso significa que para um projeto colaborativo o espaço físico precisa ser analisado no sentido de atender às necessidades dos discentes conforme as atividades previstas. $O$ tempo na organização da aula indica que o "tempo pedagógico da aula é o tempo da produção de conhecimentos e de construção das relações interativas e das atitudes e habilidades" (VEIGA, 2008, p. 290). O tempo pedagógico é o tempo organizado para fortalecer a tríade relacional professor-alunoconhecimento. A relação pedagógica entre docente e discente é mediada pelo conteúdo (VEIGA, 2008), portanto, o conhecimento é fruto dessa relação enquanto processo contínuo de construção de integração.

Todos esses elementos da organização didática da aula são marcados por aspectos técnicos, por isso, reafirma-se a necessidade de transcender o olhar para além dos elementos estruturantes de um plano. Silva (2017) e Veiga (2008) destacam a relevância dos elementos estruturantes (objetivo, conteúdo, metodologia, avaliação e recurso) para a organização didática da aula, contudo, ponderam que precisam ser integrados com a realidade social e buscar uma visão de totalidade/processo.

Freitas (1995) critica a visão linear dos processos pedagógicos em etapas que começa com os objetivos, define o conteúdo, o método e ao final a avaliação. O autor conclama dois eixos interligados: objetivos/avaliação e conteúdo/métodos. O objetivo é o fundamento para a construção da avaliação, estabelecendo uma relação indissociável que orienta todo o processo. A ideia do autor não se trata unicamente de garantir a unidade entre objetivo-conteúdo-método, tal qual garantida por Libâneo (1994), apesar da relação de interdependência entre objetivo, conteúdo e método, a questão é o lugar em que a avaliação aparece. A avaliação não surge apenas no início, mas permanece até o final do processo de ensino-aprendizagem.

A aula, para Libâneo (1994), é unidade básica, porém, como unidade, reproduz relações de poder, além de promover o distanciamento entre formação e trabalho. Consideramos a análise do autor significativa para captar a visão tecnicista da aula e seus elementos, no entanto, vale mencionar a crítica de Freitas (1995), ao analisar que a abordagem de Libâneo não mostra a categoria trabalho, apenas menciona a escola capitalista, mas não inclui as formas de organização. A categoria trabalho é um princípio educativo que precisa ser reconhecido, debatido e incorporado no universo de relações educacionais como base da compreensão da escola como produto de uma sociedade capitalista, de uma cultura de eliminação/manutenção, classificação/reprovação, inclusão/exclusão. Por essa dinâmica cabe à avaliação refletir essa unidade formando um par dialético. O par dialético avaliação/objetivos constitui categoria estruturante da organização do trabalho pedagógico que denota a função social atribuída à escola na sociedade capitalista.

\section{ALGUMAS CONSIDERAÇÕES}

A educação de uma nação é determinada historicamente nas relações sociais, políticas e econômicas. Desse modo, como expõe esse estudo, a organização do trabalho pedagógico, a partir da perspectiva capitalista, assume implicitamente e explicitamente, a fragmentação do trabalho pedagógico, do conhecimento, do currículo escolar e do planejamento e, como tal, fomenta a favor da reprodução e do individualismo. 
Em face disso, torna-se tarefa fundamental da escola superar a ideia de planejamento de ensino como atividade burocrática, com pouca utilidade, para percebê-la como um processo em constante movimento em direção a uma visão mais abrangente da organização do trabalho pedagógico da escola e da sala de aula, por conseguinte, dos níveis, concepções e práticas de planejamento. No entanto, esse é o grande desafio, transcender a compreensão, as formas e as atividades de planejamento de ensino parceladas, individuais e instrumentais.

Nesta diretriz, é preciso desenvolver um trabalho de planejamento de ensino reflexivo, coletivo, integrado, flexível e contextualizado. Não obstante, requer fazer escolhas, mudanças e redirecionar a prática constantemente, tendo em mente que o trabalho pedagógico é construído dia após dia. Deve ser reflexivo, contextualizado e flexível para possibilitar constantes revisões e articulações dos planos e projetos com base no PPP, na realidade da escola, na sociedade e nas finalidades educacionais. Deve ser, também, coletivo e integrado, voltado para uma construção coletiva a partir de uma realidade concreta que integre as especificidades da comunidade, sem perder de vista o olhar global/local.

Repensar a relevância do planejamento de ensino a fim de recuperar o seu espaço envolve uma mudança de postura, participação e compromisso de todos os profissionais da escola. Com isso, devem assumir, junto ao coletivo, os caminhos de uma educação transformadora. Portanto, reafirma-se a urgência de um planejamento de ensino para além dos elementos estruturantes de um plano de aula, que integre a escola e o contexto social na contramão da fragmentação do conhecimento, dos processos e das relações.

\section{REFERÊNCIAS}

ERCOLE, Flávia Falci; MELO, Laís Samara de; ALCOFORADO, Carla Lúcia G. C. Revisão integrativa versus revisão sistemática. Revista Mineira de Enfermagem, Belo Horizonte, v. 18, n. 1, p. 9-11, jan. mar/2014.

FREITAS, Luiz Carlos de. Organização do trabalho pedagógico. Revista Estudos, Novo Hamburgo-RS, v. 13, n. 1, p.10-18, jul. 1991.

FREITAS, Luiz Carlos de. Crítica da organização do trabalho pedagógico e da didática. Campinas: Papirus, 1995.

LIBÂNEO, José Carlos. Didática. São Paulo: Cortez, 1994.

LOPES, Antonia Osima. O Planejamento de ensino numa perspectiva crítica de educação. In: VEIGA, IIma Passos Alencastro (Org.). Repensando a didática. São Paulo: Cortez, 1991. p. 41-52.

LUCKESI, Cipriano Carlos. Avaliação da aprendizagem escolar: estudos e proposições. $22^{a}$ ed. São Paulo: Cortez, 2011.

PILETTI, Claudino. Didática geral. São Paulo: Ática, 1990.

SAVIANI, Demerval. Escola e democracia. 36ª ed. Campinas: Autores Associados, 2003.

SILVA, Edileuza Fernandes. O planejamento no contexto escolar: pela qualificação do trabalho docente e discente. In: VILLAS BOAS, Benigna (Org.). Avaliação: interações com o trabalho pedagógico. Campinas: Papirus, 2017. p. 25-38.

TURRA, Clódia Maria Godoy et al. Planejamento de ensino e avaliação. $11^{\mathrm{a}}$ ed. Porto Alegre: Sagra-DC Luzzatto, 1995.

VASCONCELLOS, Celso dos Santos. Planejamento: Plano de Ensino-Aprendizagem e Projeto Educativo elementos metodológicos para elaboração e realização. São Paulo: Libertad, 1995.

VEIGA, Ilma Passos Alencastro. Educação básica e educação superior: projeto político-pedagógico. Campinas: Papirus, 2004.

VEIGA, Ilma Passos Alencastro. Organização didática da aula: um projeto colaborativo de ação imediata. In: VEIGA, Ilma Passos Alencastro (Org.). Aula: gênese, dimensões, princípios e práticas. Campinas: Papirus, 2008. p. 267-298.

VILLAS BOAS, Benigna. O dia a dia do trabalho pedagógico: contribuições para a formação do professor 
ISSN $1983-1579$

ufpb.1983-1579.2020v13nEspecial.45583

http://periodicos.ufpb.br/ojs2/index.php

e dos estudantes. In: VILLAS BOAS, Benigna (Org.). Avaliação: interações com o trabalho pedagógico. Campinas: Papirus, 2017. p. 13-24.

Recebido em: 25/04/2019

Alterações recebidas em: 16/12/2019

Aceito em: 24/12/2019

Publicado em: $11 / 12 / 2020$ 